\title{
INTERHOSPITAL AND INTRAHOSPITAL VARIATIONS IN THE DIAGNOSIS AND SEVERITY OF SCHIZOPHRENIA
}

BY

\author{
C. MURRAY PARKES*
}

Medical Research Council Social Psychiatry Research Unit, Institute of Psychiatry, Maudsley Hospital, London

Criteria for the diagnosis of schizophrenia are not universally agreed upon and it is to be expected that clinicians at different hospitals will differ in the extent to which they assign patients to this category. However, Norris (1959) has shown that, if two clinicians examine the same patient and one diagnoses "schizophrenia", the same diagnosis will be made by the other in about 70 per cent. of cases. It would clearly be useful to know whether a similar degree of reliability could be assumed when comparing the diagnoses of patients admitted to several mental hospitals, or to the same mental hospital at different times.

This paper describes a method of rating the case notes of patients admitted to three mental hospitals in 1951 and 1956, which made it possible to evaluate changes in the admission and re-admission rates of patients diagnosed by the hospitals as "schizophrenia". It was postulated that the increase in the admission rate and re-admission rate and the decrease in the length of stay of these patients between the years 1951 and 1956 described in a previous paper (Brown, Parkes, and Wing, 1961) were due to changes in discharge policy or treatment rather than to changing fashions of diagnosis or to the admission of less severely-ill patients. A fourth hospital has been included here in order to test the reliability of the method employed.

\section{Method OF INVESTIGATION}

A random sample of the case notes of patients diagnosed "schizophrenia", who were admitted to Hospitals W, X, and Y during 1951 and 1956, and the notes of all of these patients admitted to Hospital $Z$ during 1956 were examined by the writer. The notes made at the time of the key admission (and, if necessary, at other admissions) were searched for

* Present address: Tavistock Child Development Research Unit, 2 Beaumont Street, London, W.1. evidence of the following symptoms:

I. SyMPTOMS STRONGLY SUPPORTING DiAgNosis OF SCHIZOPHRENIA*

1. Ideas of Change in Self attributed to external influence.

2. Feelings of Passivity, control from without or under external influence, Abulia.

3. Feelings of Telepathy, of thoughts being read or of reading the thoughts of others.

4. Disorder of Speech and Thinking, characterized by lack of connection between one thought and the next, dysymbole, blocking, stereotypy, ellipsis, metonymy, asyndesis, interpenetration, bizarre content, neologisms, inappropriateness, lack of consensual validation, overinclusion.

5. Catatonic Disturbance of motor functions and behaviour.

6. Incongruity, Inappropriateness or Flattening of Affect.

7. Delusions of Persecution (plus hallucinations of persecutory voices or ideas of reference), provided these are not believed to be deserved or to be a punishment for some real or imagined crime.

8. Bizarre Delusions, Impossible and Extracampine Hallucinations.

II. Symptoms Detracting From Diagnosis of SCHIZOPHRENIA

1. Prominent Affective Symptoms not describable as labile (lasting less than 12 hours), incongruous or flat.

* The method employed for rating "certainty of diagnosis" is based on a similar method devised by Wardle (1960). It employs a standard list of symptoms which are usually regarded as pathognomonic of schizophrenia. These are derived mainly from the work of Bleuler (1924), Cameron (1944), and Langfeldt (1937). 
2. Clouding of Consciousness or Disorientation.

3. Neurotic Manifestations.

Whenever one of these symptoms was found, it was recorded, and after assessment the patient was assigned to one of three categories according to "the certainty" of the diagnosis.

(i) Probable Schizophrenia.-Clear evidence of symptoms supporting diagnosis of schizophrenia (list I).

(ii) Doubtful Schizophrenia.-Symptoms of List I not present on key admission but present at other admissions;

or

Symptoms of List I present but not marked, whereas symptoms of List II clearly present and marked.

(iii) Diagnosis of Schizophrenia not Confirmed.No symptoms from List I.

The use of these terms can best be illustrated by taking some examples as they were recorded from the hospital notes during the investigation.

\section{EXAMPLES}

(i) Cases rated "Probable Schizophrenia"

CASE 1. "Marked thought disorder". Does not feel "solid", speech disjointed and off the point. Extremely vague. "Talks confusedly with abrupt changes of topic". "Thought blocking".

CASE 2. Powerless under the influence of other people. Tried to strangle girl friend but couldn't say why.

CASE 3. Stereotyped rubbing of back below left shoulder, thereby wearing holes in her clothes.

CASE 4. Giggling incongruously. "Extreme affective blunting". Manneristic and withdrawn.

\section{(ii) Cases rated "Doubtful Schizophrenia"}

CASE 5. Depressed, believes that people are making signs at her and trying to tell her something.

CASE 6. Smiles and laughs inappropriately and states that she is a changeling.

CASE 7. Depressed and retarded on admission but had previously thought that people were plotting to destroy him, accused mother of murder and smashed a wireless set.

CASE 8. Vague delusions of persecution by neighbours and marked flattening of affect, disorientated.

(iii) Cases rated "Diagnosis of Schizophrenia not Confirmed"
CASE 9. Agitated and depressed. Said to be "paranoid" but only evidence for this the statement that she felt "hard done by". Subsequently had attack of hypomania.

CASE 10. Depressed. Convinced that she is contaminated with disinfectant and will in turn contaminate everything she touches. Several previous attacks of depression.

CASE 11. Depression and depersonalization.

CASE 12. In a state of excitement with grandiose delusions, flight of ideas, and overactivity.

It will be apparent from these examples that "clear evidence" is more easy to obtain for some symptoms than for others. Thus the notes commonly described "Flattening of Affect", but the detection of this symptom is very likely to be influenced by observer bias; consequently it was not normally regarded as of sufficient reliability to justify placing the patient in the "Probable" category unless other evidence could be found to support the diagnosis. Similarly references to "Thought Disorder" were not accepted as clear evidence of schizophrenic disorder of speech and thinking unless the notes also contained other details or verbatim reports which confirmed this. Another group of symptoms which are not always easy to assess from the notes comprises "Delusions of Persecution", which tended to merge with paranoid ideas and attitudes. Unless these were very prominent and associated with auditory hallucinations of persecutory voices or ideas of reference they were not sufficient to justify placing the case in the "Probable" category. In fact there was some evidence of ideas of persecution in two-thirds of the patients in both the "Probable" and the "Doubtful" categories, whereas "Ideas of Change in the Self" and "Feelings of Telepathy", whilst less common, were confined to patients assigned to the "Probable" category.

In addition, the severity of the symptoms imfrediately preceding the key admission was assessed mom the notes and patients were classified under two headings:

(1) Crisis Admission-Violence, mutism, or gross disturbance of behaviour.

(2) Non-crisis Admission-All other admissions.

In order to test the reliability of these ratings the assessments at Hospital $Z$ were repeated by an independent assessor (Dr. J. K. Wing re-assessed "Certainty of Diagnosis" and Dr. D. B. Coates re-assessed "Severity on Admission"). 


\section{ResUlTS}

\section{Reliability of Ratings at Hospital Z.}

Certainty of Diagnosis.-Table I shows how the two assessors assigned patients to the three "Certainty of Diagnosis" categories. There was complete agreement in 68 per cent. of cases (144/211) and when "Doubtful" and "Not Confirmed" groups were combined the level of agreement reached 79 per cent. (167/211). Disagreement was greatest concerning patients in the "Doubtful" category, and scrutiny of the notes of discrepant cases suggests that the difficulty lay in deciding what constituted "clear evidence" of the symptoms in List I. It is thought that the reliability of the method could be improved if the meaning of this term for each symptom and combination of symptoms was previously defined and the raters were trained in the use of these operational definitions. This would greatly complicate the method and would, perhaps, over-refine a technique which, as the present study shows, is quite adequate to the purpose for which it was designed.

TABLE I

RELIABILITY OF "CERTAINTY OF DIAGNOSIS" RATINGS COMPARISON OF RAT NGS MADE BY C.M.P. AND J.K.W. AT HOSPITAL Z. BOTH SEXES. 1956 ADMISSIONS

\begin{tabular}{|c|c|c|c|c|c|c|}
\hline & & & \multicolumn{4}{|c|}{ Ratings by J.K.W. } \\
\hline & & & $\begin{array}{c}\text { Prob- } \\
\text { able }\end{array}$ & $\begin{array}{l}\text { Doubt- } \\
\text { ful }\end{array}$ & $\begin{array}{l}\text { Not } \\
\text { Con- } \\
\text { firmed }\end{array}$ & Total \\
\hline \multirow{4}{*}{$\begin{array}{c}\text { Ratings } \\
\text { by } \\
\text { C.M.P. }\end{array}$} & Probable & .. & 64 & 6 & 8 & 78 \\
\hline & Doubtfu & . & 13 & 5 & 7 & 25 \\
\hline & \multicolumn{2}{|c|}{ Not Confirmed } & 17 & 16 & 75 & 108 \\
\hline & Total & $\ldots$ & 94 & 27 & 90 & 211 \\
\hline
\end{tabular}

Severity on Admission.-Table II shows agreement between the two assessors who allotted patients to the "Severity on Admission" categories. Only the female patients were taken into account. Agreement was reached in 79 per cent. of cases (111/141).

TABLE II

RELIABILITY OF "SEVERITY ON ADMISSION" RATINGS COMPARISON OF RATINGS MADE BY C.M.P. AND D.B.C. AT HOSPITAL Z

FEMALE PATIENTS ONLY. 1956 ADMISSIONS

\begin{tabular}{|c|c|c|c|c|c|}
\hline & & & \multicolumn{3}{|c|}{ Ratings by D.B.C. } \\
\hline & & & $\begin{array}{c}\text { Crisis } \\
\text { Admission }\end{array}$ & $\begin{array}{l}\text { Non-Crisis } \\
\text { Admission }\end{array}$ & Total \\
\hline \multirow{3}{*}{$\begin{array}{l}\text { Ratings } \\
\text { by } \\
\text { C.M.P. }\end{array}$} & $\begin{array}{l}\text { Crisis } \\
\text { Admission }\end{array}$ & .. & 25 & 6 & 31 \\
\hline & $\begin{array}{l}\text { Non-Crisis } \\
\text { Admission }\end{array}$ & . & 24 & 86 & 110 \\
\hline & Total .. & . & 49 & 92 & 141 \\
\hline
\end{tabular}

The reliability of these assessments is regarded as satisfactory.

\section{Differences betWeEn the Four Hospitals}

"Certainty of Diagnosis".- These ratings at the four hospitals are shown in Table III, in which only the admissions in 1956 are taken into account and both sexes are combined. At Hospital W, 69 per cent. of the sample of case notes were assessed as indicating "Probable Schizophrenia". The equivalent proportions at Hospitals $\mathrm{X}$ and $\mathrm{Y}$ were 73 per cent. and 72 per cent., but only 47 per cent. at Hospital Z.

TABLE III

CERTAINTY OF DIAGNOSIS OF SCHIZOPHRENIA FOUR HOSPITALS COMPARED. 1956 ADMISSIONS ONLY

\begin{tabular}{|c|c|c|c|c|c|c|c|c|}
\hline \multirow{3}{*}{$\begin{array}{l}\text { Certainty of } \\
\text { Diagnosis }\end{array}$} & \multicolumn{8}{|c|}{ Hospital } \\
\hline & \multicolumn{2}{|c|}{$\mathbf{W}$} & \multicolumn{2}{|c|}{$\mathbf{x}$} & \multicolumn{2}{|c|}{$\mathbf{Y}$} & \multicolumn{2}{|c|}{$\mathbf{Z}$} \\
\hline & No. & $\begin{array}{c}\text { Per } \\
\text { cent. }\end{array}$ & No. & $\begin{array}{l}\text { Per } \\
\text { cent. }\end{array}$ & No. & $\begin{array}{l}\text { Per } \\
\text { cent. }\end{array}$ & No. & $\begin{array}{l}\text { Per } \\
\text { cent. }\end{array}$ \\
\hline Probable & 66 & 69 & 54 & 73 & 57 & 72 & 98 & 47 \\
\hline Doubtful & 20 & 21 & 11 & 15 & 6 & 8 & 28 & 13 \\
\hline Not Confirmed & 10 & 10 & 9 & 12 & 16 & 20 & 85 & 40 \\
\hline Total & 96 & 100 & 74 & 100 & 79 & 100 & 211 & 100 \\
\hline
\end{tabular}

"Severity on Admission"-Only admissions in 1956 are taken into account and both sexes are combined.

"Crisis Admissions" occurred in 24 per cent. (23/96) from Hospital W, 8 per cent. (6/74) from Hospital X, 10 per cent. (8/79) from Hospital Y, and 18 per cent. (38/123) from Hospital $Z$.

When the "Certainty of Diagnosis" ratings for each hospital were examined separately in each of the "Severity" categories, it was found that there was little difference between hospitals in the diagnostic ratings of patients in the "Crisis Admission" group, but that there were marked differences between the ratings of the less-severely disturbed patients. The proportions of patients rated "Probable Schizophrenia" in the "Crisis Admission" group were: W 71 per cent., X 61 per cent., Y 71 per cent., and Z 72 per cent.; but in the "Non-crisis Admission" group they were: W 70 per cent., $X 72$ per cent., $Y 77$ per cent., and $Z 41$ per cent. $\left(\chi^{2} 55 \cdot 2 ; 3\right.$ d.f.; $P<0.001)$.

Thus assessments of the case notes of patients diagnosed "Schizophrenia" at Hospital $Z$ differ from those at Hospitals $\mathrm{W}, \mathrm{X}$, and $\mathrm{Y}$, in that there is 
a larger proportion of unconfirmed diagnoses among patients whose illness on admission was not severe enough to constitute a "Crisis Admission".

\section{Differences Within Hospitals W, X, and Y*}

Age and Sex.-Neither "Certainty of Diagnosis" nor "Severity on Admission" was significantly affected by the age or sex of the patient.

Diagnosis.-Comparison between the years 1951 and 1956 revealed very little difference. 73 per cent. of patients (119/164) were rated "Probable Schizophrenia" in 1951 compared with 71 per cent. $(177 / 249)$ in 1956 , and there were 21 per cent. of "Crisis Admissions" in 1951 compared with 15 per cent. in 1956. None of these differences was statistically significant.

Length of Stay.-There was a decrease in the proportion of patients retained for over 2 years after admission between the years 1951 and 1956, but this was not confined to the less severely-ill patients. 43 per cent. of the "Crisis Admission" group were retained for over 2 years in 1951 compared with 6 per cent. in 1956, and the corresponding figures for the "Less Severe" group were 29 and 8 per cent. (Table IV). Thus the change in 1956 was due to the earlier discharge of patients of both grades of severity.

TABLE IV

SEVERITY OF ILLNESS ON ADMISSION, BY OUTCOME 1951 AND 1956 COHORTS COMPARED HOSPITALS $W, X$, AND Y COMBINED

\begin{tabular}{|c|c|c|c|c|c|c|c|}
\hline \multirow{3}{*}{$\begin{array}{l}\text { Co- } \\
\text { hort }\end{array}$} & \multirow{3}{*}{ Outcome } & \multicolumn{6}{|c|}{ Severity of Illness on Admission } \\
\hline & & \multicolumn{2}{|c|}{$\begin{array}{c}\text { Crisis } \\
\text { Admission }\end{array}$} & \multicolumn{2}{|c|}{$\begin{array}{l}\text { Non-Crisis } \\
\text { Admission }\end{array}$} & \multicolumn{2}{|c|}{ Total } \\
\hline & & No. & $\begin{array}{c}\text { Per } \\
\text { cent. }\end{array}$ & No. & $\begin{array}{c}\overline{P e r} \\
\text { cent. }\end{array}$ & No. & $\begin{array}{l}\text { Per } \\
\text { cent. }\end{array}$ \\
\hline \multirow{3}{*}{1951} & Retained $>2$ years & 12 & 43 & 34 & 29 & 46 & 32 \\
\hline & $\begin{array}{c}\text { Discharged within } \\
2 \text { years }\end{array}$ & 16 & 57 & 82 & 71 & 98 & 68 \\
\hline & Total & 28 & 100 & 116 & 100 & 144 & 100 \\
\hline \multirow{3}{*}{1956} & Retained $>2$ years & 2 & 6 & 15 & 8 & 17 & 8 \\
\hline & $\begin{array}{c}\text { Discharged within } \\
2 \text { years } \ldots\end{array}$ & 33 & 94 & 171 & 92 & 204 & 92 \\
\hline & Total & 35 & 100 & 186 & 100 & 221 & 100 \\
\hline
\end{tabular}

28 patients who were discharged to addresses outside London are not included in this Table.

$1951 x^{2}=1 \cdot 9 ;$ d.f. $1 ; 0.1<p<0.2$
$1956 x^{2}=0.2 ;$ d.f. $1 ; 0.5<p<0.7$.

- Hospital $\mathbf{Z}$ was not included in this part of the study.

\section{Discussion}

The reliability of this method of making retrospective assessments of the diagnosis of schizophrenia from case notes has been established, but the validity of the assessments is less clear. It might be possible to explain the differences between the four hospitals in terms of the quality of the records, but Hospital Z seemed to have a higher standard of notetaking than the other three hospitals, so that it is unlikely that the larger proportion of unconfirmed diagnoses at this hospital is due to poor note-taking. It is more probable that the psychiatrists at Hospital $Z$ have a wider concept of "Schizophrenia" than those at Hospitals W, X, and Y.

The psychiatrists at Hospitals $\mathrm{W}, \mathrm{X}$, and $\mathrm{Y}$ are thought to have had a consistent concept of schizophrenia which did not change between 1951 and 1956 and was not markedly affected by the age or sex of the patient.

"Crisis Admissions" occurred almost as frequently in 1956 as 1951 and the incidence of these was not related to the age or sex of the patients.

It is concluded that the findings described by Brown and others (1961) in the previous study (viz. a dramatic increase between the years 1951 and 1956 in the number of patients diagnosed "Schizophrenia" who were admitted to hospitals $\mathrm{W}, \mathrm{X}$, and $\mathrm{Y}$; a marked increase in the discharge rate; a similar increase in the re-admission rate; and a great reduction in the proportion of schizophrenic patients retained for over 2 years) could not be accounted for by a tendency to admit less severely-ill patients or a change in the type of patient who is labelled "Schizophrenic". They are probably explained by a changing discharge procedure or the introduction of new methods of treatment.

The change in the retention rate of the "Crisis Admission" group between 1951 and 1956 seems to reflect an increasing tendency to discharge to the community patients who would in the past have been retained for considerable lengths of time.

\section{SUMMARY}

(1) A method of assessing the "Certainty of Diagnosis" and "Severity on Admission" on admission of patients diagnosed as "Schizophrenia", using mental hospital case notes, is described.

(2) Two assessors agreed in assigning patients to one of three "Certainty of Diagnosis" categories in 68 per cent. of cases and to one of two "Severity on Admission" categories in 79 per cent. The reliability of the method of assessment is thought to be satisfactory. 
(3) A much larger proportion of case notes at Hospital $\mathrm{Z}$ were assessed as indicating doubtful or unconfirmed diagnoses of schizophrenia than at Hospitals W, X, and Y.

(4) There were no marked differences between the "Certainty of Diagnosis" and "Severity on Admission" ratings of patients admitted to Hospitals $W, X$, and $Y$ in 1951 and 1956, or in patients from different sex and age groups.

(5) Increases in the admission, discharge, and readmission rates of schizophrenic patients between 1951 and 1956 at these three hospitals cannot be accounted for in terms of a change in the fashions of diagnosis or in the severity of illness of the patients admitted.

(6) A reduction in the length of stay was found among patients of both grades of severity. Only 6 per cent. of the "Crisis Admission" group of the 1956 cohort were retained in hospital for over 2 years compared with 43 per cent. of the same group in the 1951 cohort.
I should like to thank Dr. G. W. Brown, Dr. D. B. Coates, and Dr. J. K. Wing for their help in the planning and execution of this study, and the medical superintendents of the four mental hospitals for allowing free access to their case records.

\section{REFERENCES}

Bleuler, E. P. (1924). "Dementia Praecox or the Groups of Schizophrenias", trans. J. Zinkin. International University Press, New York.

Brown, G. W., Parkes, C. M., and Wing, J. K. (1961). J. ment. Sci., 107, 1070.

Cameron, N." (1944). In "Language and Thought in Schizophrenia", ed. J. S. Kasanin, p. 50. University of California Press, Berkeley and Los Angeles.

Langfeldt, G. (1937). "The Prognosis in Schizophrenia and the Factors Influencing the Course of the Disease", Acta psychiat. neurol., Suppl. 13. Oxford University Press, London.

Norris, V. (1959). "Mental Illness in London". (Maudsley Monographs, No. 6). Chapman and Hall, London.

Wardle, C. (1960). "Social Achievement and the Functional Psychoses". M.D. Thesis, University of London. 